\title{
РЕЦЕНЗИИ
}

\author{
Д. Ю. Ващенко \\ Институт славяноведения РАН \\ (Москва, Россия) \\ daranis@mail.ru
}

\section{P. ŽIGO. VÝVIN SUBSTANTÍVNEJ DEKLINÁCIE V SLOVANSKÝCH JAZYKOCH (BRATISLAVA. UNIVERZITA KOMENSKÉHO V BRATISLAVE. 2017. 116 S.)}

Монография П. Жиго «Развитие субстантивного склонения в славянских языках» вышла в Братиславе в 2017 г. Книга сравнительно невелика по объему (чуть более 100 страниц), однако является чрезвычайно ёмкой и насыщенной как в теоретико-методологическом отношении, так и в плане представленного фактического материала. В ней словацкий лингвист продолжает разрабатывать свою концепцию эволюции субстантивного склонения в естественных языках, очерченную еще в предыдущих исследованиях, напр., в монографии «Аналогии и аномалии в развитии субстантивного склонения» ${ }^{1}$. На этот раз П. Жиго, по его словам, хочет сосредоточиться на типологическом аспекте изменений в субстантивном склонении. Монография состоит из трех разделов, каждый из которых в свою очередь состоит из нескольких глав, при этом сами разделы лишь пронумерованы, а отдельные главы уже имеют названия, носящие при этом подчеркнуто философский, полемический характер. Книга основывается на материалах морфологической части Общеславянского лингвистического атласа. В ней автор отнюдь не стремится дать исчерпывающее описание славянского субстантивного склонения, для него важно наметить и аргументированно обосновать те теоретико-методологические принципы, которые позволят сделать подобное описание, с учетом материала и задач такого рода исследований, максимально адекватным.

Первый раздел носит вводный характер и состоит из трех глав. В первой главе «Исходные положения интерпретации» П. Жиго говорит о необходимости применения комплексного подхода при изучении субстантивного склонения - это касается как совмещения семантического и морфонологического критериев при интерпретации форм, так и синтеза генетически и ареально ориентированных подходов. Кроме того, словацкий исследователь пишет о важности приложения оппозиции

${ }^{1}$ P. Žigo. Analógie a anomálie vo vývine substantívnej deklinácie. Bratislava. 2012. 
«свой / чужой» к материалу диахронической морфологии, когда часть собственных элементов в процессе развития вытесняется чужими, при этом решающее значение имеет функциональность конкретного элемента. В следующей главе, «Смена парадигмы: от формы к значению» рассматриваются возможные подходы к трактовке дублетности форм в том или ином языке, подчеркивается, что в лингвистике наблюдается переход от чисто фонологических интерпретаций к семантико-синтаксическим истолкованиям. При этом, как утверждает П. Жиго, на современном этапе подобного рода исследования могут и должны быть верифицированы корпусно-статистическими данными, которые будут предоставлять информацию о фактической распространенности того или иного варианта в национальном языке а также социолингвистически и когнитивно ориентированными разработками: те, в свою очередь, призваны определить значимость той или иной вариантной формы прежде всего с позиции пользователей языка. Высказываемые положения П. Жиго иллюстрирует на примере подобного комплексного анализа развития флексии Р. п. ед. ч. м. p. -a / -u, причем не только на словацком материале, вернее, словацкий материал здесь трактуется исследователем в максимально широком контексте, в том числе с привлечением картографических материалов ОЛА. В третьей главе «Стабилизация морфологических структур» П. Жиго пишет, что в словацком языке влияние грамматического рода на трансформацию субстантивного склонения проявилось, в отличие от иных славянских языков, не только на внутрипарадигматическом, но также на межпарадигматическом уровне (ср. флексии Д. п. ед. ч. м. р., также Р. П. мн. ч. ж. р.), и вместе с тем в ходе развития субстантивного склонения, как показывают материалы в т. ч. ОЛА, в регионах Славии сформировались новые ареалы, не совпадающие с классическим членением славянских языков на восточно-, западно- и южнославянские.

Второй раздел занимает в монографии центральную позицию. Его первая глава носит название «От хаоса к бифуркациям», в ней П. Жиго стремится дать широкую прежде всего философскую интерпретацию стихийности языковых изменений, релевантными для него представляются два аспекта хаоса как фундаментальной философской категории: темпоральный хаос, который онтологически предшествует системности (в языке) и периодически приходит ей на смену 一 и квантитативноквалитативный хаос, который характеризуется синхронной нечеткостью, асистемностью. В применении к языковому материалу, пишет автор, первый аспект приобретает роль своего рода «спускового механизма», здесь невозможно говорить о каком-либо предшествовании / чередовании, но темпоральный хаос предстает как несоотносимость, разноплановость тех или иных элементов языковой структуры в разные периоды времени, когда изменения происходят постепенно и неравномерно - и вместе с тем как движущая сила преобразований в языке. Со вторым, т. е. с квантитативно-квалитативным хаосом, связан тот факт, что в результате подобных, квази-хаотичных трансформаций языковая система становится чрезвычайно гибкой и чувствительной к новым изменениям, и в итоге переходит от изоляции к открытости и дивергентности, постепенно формируются системы (парадигмы), оптимально соответствующие новым функционально-коммуникативным критериям 
в языке, который оказывается тесно связан с социально-историческими и культурными изменениями, хаос тем самым выступает как часть порядка и даже как один из его конституентов. Вторая глава носит подчеркнуто полемический характер, что о чем говорит и её название: «Бифуркации или мультифуркации?», в ней словацкий лингвист, развивая тезис о неравномерности языковых изменений, утверждает, что, хотя вариативность субстантивного склонения по-разному проявила себя в различных славянских языках — где-то сильнее, где-то менее явно — в словацком языке она получила наиболее широкое развитие. П. Жиго постулирует здесь значимость рассмотрения языковых явлений в макроструктурной проекции, а также необходимость применения ареального критерия в его комплексной комбинации с собственно генетическим как методологического принципа при исследовании истории субстантивного склонения. Третья глава «Диспропорции генетической - ареальной - типологической классификации» напрямую развивает положения, высказанные в предыдущей главе в т. ч. на богатом материале морфологических карт ОЛА (Д. П. ед. ч. названий животных, Предл. п. ед. ч. слова syn, Д. п. ед. ч. субстантива host' и др.) Как пишет автор, нельзя говорить об однозначном доминировании ареального либо типологического критерия при анализе языков Славии, но скорее о многомерности системы, когда на первый взгляд противоположные векторы взаимно дополняют и взаимно обогащают друг друга, речь в данном случае идет не столько о новациях или отклонениях, сколько о различных сосуществующих тенденциях. Четвертая глава «Социальная и культурная континуальность» посвящена проблеме естественности, вернее, неестественности в языке. П. Жиго вновь обращается к философскому аспекту проблемы, рассматривая три возможных трактовки не-естественности, когда сама естественность может рассматриваться как статическая, как комплексная и полифакторная, либо же как принципиально открытая конструкция: на морфологическом уровне это проявляется, во-первых, в необходимости верифицировать диахронический срез социолингвистически ориентированными исследованиями, и, во-вторых, в понимании естественности той или иной флексии как ее функциональной оптимальности (ср., например, карту ОЛА kolo / koleso и др.). В пятой главе «Поэтому мультифуркации» П. Жиго подводит черту под тезисами, которые он последовательно развивал в предшествующем изложении. То, что в начале языковых изменений предстает как хаос, постепенно приобретает системный характер, так что в ретроспективе можно уже в первоначальном хаосе определить будущие системообразующие знаки, и поскольку новая система может нести в себе элементы совершенно разного порядка, имеет смысл говорить не о би-фуркациях, но о мультифуркациях.

Третья, заключительная часть открывается главой «Инородность и чуждость современное «открытие» или natura stabilis», где П. Жиго подчеркивает, что в национальных славянских языках значительную роль играют не только конвергентные, но и дивергентные процессы, именно поэтому материал ОЛА помогает увидеть явление в широкой ареально-типологической перспективе, и, кроме того, «достроить» те фрагменты языковой системы, которые недостаточно полно зафиксированы в письменных источниках. Немаловажную роль здесь сыграла 
социокультурная ситуация, когда во многих регионах Славии преобладало смешанное население, среди которого локальная идентичность превалировала над этнической, тем самым часть элементов в том или ином славянском языке подвергалась внешнему давлению, носившему не столько экспансивный, сколько инфильтративный характер. Наиболее рельефно указанная тенденция проявляется в области лексики, но это не означает, что она никак не проявляет себя на уровне грамматики. Вторая глава третьей части носит название «Современное понимание естественности, инородности и чуждости», в ней П. Жиго на новом материале представляет положение о том, что естественность в применении к языковому материалу означает естественность прежде всего для пользователя языкового идиома, иными словами, функциональность: именно функциональный критерий составляет тот фильтр, через который проходят элементы языковой структуры в ходе эволюции. Наконец, в третьей главе «Противоречия и перспективы» словацкий исследователь пишет о том, что языковое развитие представляет собой процесс открытый, который на разных уровнях отличается различной мерой стабильности менее в области лексики, гораздо сильнее в области морфологии - и материал ОЛА поможет определить как сущность процесса в диахронии, так и его возможную перспективу в будущем.

Книгу дополняет приложение, где приводятся все основные типы праславянского субстантивного склонения. Монография П. Жиго чрезвычайно насыщена иллюстративным материалом - помимо карт ОЛА, сюда относятся многомерные диаграммы и графики, а также системы граф, демонстрирующие соотношение между исходным праславянским состоянием и нынешним положением дел в словацком литературном языке.

Глубина философской проблематики, ценность высказываемых теоретических положений, широкая эмпирическая база, а также энциклопедический кругозор автора делают данную монографию ценной для российского читателя. Представляется чрезвычайно актуальным последовательно разрабатываемый автором тезис о том, что лингвистика на современном этапе должна стремиться к комплексному описанию, когда различные подходы, равно как и различные страты в языке, не исключают, а взаимно дополняют друг друга: лишь в этом случае возможно получить многомерный образ, максимально приближенный к реальной действительности. Монография напрямую подводит также к проблеме вариативности в языке и дублетности форм, которые в данном случае предстают не как случаи нарушения нормы, но как результат естественного развития, а вариативность становится функционально мотивированной и потому естественной. Новую интерпретацию получает понимание «иного» в языке: чужое предстает не как некая противодействующая сила, а как движущая энергия языкового развития. Монография открывает широкую перспективу дальнейших разработок, когда полифакторное исследование позволит сделать ценные и при этом точные обобщения на базе материала в т. ч. Общеславянского лингвистического атласа, а введение социолингвистических и ареально-типологических параметров позволит соотнести результаты исследования с материалом соседних неславянских языков. 